\title{
Trauma survivors and the media: A qualitative analysis
}

\author{
Tamara K. Cherry*
}

\begin{abstract}
While much has been written about how the media covers traumatic events, little is known about the impact of the media on trauma survivors. This, despite the fact that crime coverage has been a staple of daily news cycles for several decades. Likewise, little has been written about the training and methods of the journalists who cover these events, or the impact of this coverage on the journalists. Based on 71 qualitative surveys and interviews with homicide and traffic fatality survivors, and 22 qualitative surveys of journalists, this article serves to describe five main themes regarding survivor experiences: 1) Prior experience with the media; 2) First encounters with the media; 3) Negative impacts of the media; 4) Positive impacts of the media; and 5) Advice for various stakeholders. Additionally, this article will describe three main themes highlighted by the journalists: 1) Trauma-informed training and guidelines; 2) Comfort in contacting survivors; and 3) Personal impact of reporting on trauma. These findings illustrate a clear gap in services available to survivors, in particular in the immediate aftermath of traumatic events when media attention is often at its highest, as well as a lack of support for journalists covering these events.
\end{abstract}

Key Words Victimology; journalism; survivor support; criminal justice; trauma-informed; homicide; traffic fatalities.

\section{INTRODUCTION}

Crime has long been a point of public interest. It leads newscasts, fills front pages, and provides content for popular podcasts and documentary series. Victims and survivors often play a central role in these forms of storytelling: the video of the anguished mother running toward police tape; the interview with the father holding a photo of his daughters who were killed in a street-racing crash; the distraught family member placing flowers at the scene of the city's latest homicide. And while consumers of these stories have no doubt imagined the impact of the crimes on the survivors, rarely has the public seen the impact of the media coverage on these same people.

Documents have been prepared to guide journalists who cover these sorts of events (Bucqueroux \& Seymour, 2009), as well as victims and survivors who find themselves in the media spotlight (Considerations for victims, 2011). Many researchers have analyzed how journalists cover traumatic events (Durham et al., 1995; Shepard, n.d.; Newton \& Duncan, 2012; Schildkraut, 2012), but it is difficult to find research that explores the impact on survivors. This project set out to do just that.

I was a crime reporter in Toronto for nearly 15 yearsfirst at the Toronto Star, then the Toronto Sun, and finally, for the bulk of my career, at CTV News Toronto. Though I never received any formal trauma training, either in journalism school or on the job, much of my time was spent telling the stories of trauma survivors, often in the wake of homicides and traffic fatalities.

In late 2019, I left CTV to launch Pickup Communications, a public relations firm that supports victims and survivors of traumatic events. It was through this lens that I began this qualitative study in May 2020. My hope is that this work will spark conversations between stakeholders in the criminal justice, news media, and survivor support sectors as they not only examine their own practices, but brainstorm ways they can work together.

\section{METHODS}

This article is based on structured surveys (created and accessed through the Survey Monkey platform) and qualitative interviews with trauma survivors and journalists who cover trauma. Canada and the United States were chosen as the target research areas for their similarities in the types of crimes covered, journalist training, and the supports available to victims and survivors. 
The first survey discussed in this paper was created for survivors of homicide and traffic fatalities. Participants for this survey were recruited from various bereavement support groups across Canada and the United States, advertising on social media, and a handful of homicide survivors on whom the author had reported as a journalist. The survey was comprised of 27 open-ended questions focusing on the survivors' experiences with the media in the immediate and, when applicable, long-term, aftermath of their traumatic loss, and asking what advice they would share with various stakeholders. The survey period was from June 2020 to February 2021. There were 45 respondents from Canada, 25 from the United States, and 1 from New Zealand. Together, they represented 59 separate homicide cases and 14 traffic fatality cases. One case dated from the 1970s, five from each of the 1980s and 1990s, and the remaining 62 were from the 2000s (17), 2010s (39) and 2020s (6).

The survey administered to journalists who cover trauma touched on several topics, including training, common practices, and the personal impact on respondents. It was made up of 30 open-ended, multiple choice, and check-all-that-apply questions. This survey was distributed to reporters personally known to the author and advertised through social media, including in a Facebook group for journalists who cover trauma. Between July 2020 and February 2021, 17 Canadian journalists and 5 American journalists completed this survey. Their experience in the profession ranged from between 5 and 10 years to more than 20 years. Each of the 22 respondents indicated that they currently reported (or had reported, for those who were retired) on trauma at least once a year, 19 of them at least once a month, five of them on a daily basis, and two of them more than once per day.

In addition to the surveys, in-depth interviews were conducted with several survivors who are quoted in the body of the paper. As is common in qualitative studies, participants were given license to let their experiences shape the direction of the conversations. Due to COVID-19 restrictions, all interviews were done over the phone or video chat.

Basic tabular data was used to identify similarities and differences in the data derived from the surveys and to verify the overall strength of patterns in the data. This method also helped identify cases that deviated from observed patterns. While the statistical data in this article is drawn from the surveys, context is derived from both the surveys and interviews, as well as the author's personal observations as a crime reporter. Participants provided informed consent, and pseudonyms were used to protect their identity. Overall, participants in all categories overwhelmingly declared that they were grateful for the study, that they are hungry for change, and that these conversations are long overdue.

\section{RESULTS}

\section{Survivors}

\section{Prior Experience with the Media}

Of the 71 homicide and traffic fatality survivors, 56 indicated they had had no encounters with the media prior to their traumatic loss(es). Nine of them indicated they had had limited experience, including some who had been interviewed for local news stories as children or regarding their businesses as adults. Five had undergone formal media training as part of their professional lives.

No trends emerged regarding a correlation between prior media experience and the likelihood of having a more positive or negative experience with the media after the traumatic loss. For example, Tracy, whose son had been killed in a mass casualty collision in Canada in recent years, told me she had both undergone and delivered media training in her role at a large, publicly traded company. In an interview, she said that her prior professional experience had informed her decisions in the days and weeks that followed her son's death:

I knew myself. I'm not going to do media...when I haven't slept and I haven't eaten and I'm going to be incoherent and not tell stuff right, but that's because I have prepped enough executives over my 12 years that [I know] you can say the wrong things or stuff gets misconstrued.

Around the same time, an American homicide survivor who worked as a communications spokesperson described not being prepared for the onslaught of media coverage when her ex-husband murdered his wife and two daughters before killing himself. She wrote in her survey that the intense media coverage made her feel "Horrible. As though the story would never end." In describing a negative experience with misinformation being reported in the case of her nephew-a 14-year-old Canadian homicide victim-Barbara wrote that her previous encounters with reporters as a community advocate gave her "good standing with the media," and the knowledge that "they needed to be talked to as corrections needed to be made." She later added, "When the media was able to understand the story, then (my nephew's) story was told properly."

\section{First Encounters with the Media}

Of the 71 homicide and traffic fatality survivors who completed a survey, 44 indicated they were contacted by members of the media within the first 72 hours of the death of their loved one(s). Fifty respondents described their first experience with the media-be it an encounter with a reporter or consuming the media coverage of their case-as negative, while 15 described it as positive. Six described it as neither positive nor negative.

Several respondents described being contacted by members of the media within hours of their traumatic loss; many described reporters using several methods to contact them.

\section{Negative Impacts of the Media}

Of the 71 homicide and traffic fatality survivors who completed the survey, all but 6 reported at least one negative outcome. Thirty-eight respondents described the media as contributing to their trauma. Of the 40 negative categories that emerged from the surveys, this was the one reported most often. The second most-cited negative impact was the reporting of misinformation (25), followed by upsetting images or details (19), privacy concerns (14), lack of follow-up (12), and perceived harassment by members of the media (11).

The emotion that surfaced most often was the feeling of being angry or furious (20), followed by hurt, sad, or demoralized (16). Eight people reported feeling vulnerable; the same number reported feeling afraid. 
Seven survivors reported that the media had had a direct, negative, long-term impact on them personally, including Heather, whose husband, a Canadian police officer, was murdered while on the job, and who wrote: "I am shy and private, and the exposure and invasion of my privacy, my family, my children, [my husband]'s death added to the trauma and has changed me forever."

Several respondents described the resurfacing of their trauma due to the retelling of their story in the media, in particular when the coverage was prolonged or unexpected. Beverly, whose daughter's homicide remained in the news cycle for six years, wrote in her survey: "Every time there is another story or a mention of her, there is an overwhelming sense of loss all over again."

Melissa, whose sister was murdered in March 2003, described in her survey watching the news several months later when a "year in review" came on screen: "I watched my sister come out of the house in a body bag. I didn't even know they had that coverage. I was horrified, and thankful my parents didn't see that." Melissa was one of 19 survivors who reported upsetting images or details in the media coverage of their traumatic loss(es). Bridgette described an early report of her son's murder "that mentioned him being found in a pool of his own blood; this creates a heartrending brutal visual for bereaved parents." Barb, whose husband was killed in the World Trade Center on 9-11, wrote that she continues "to see visuals of the planes flying into the towers." Homicide survivor Katie wrote that while she had many positive experiences with the media, it was upsetting to see repeated use of images depicting the three knives used to kill her son.

Some survivors described being upset by the pictures that were used of their loved one, including an American homicide survivor who said investigators released her son's public-intoxication arrest photo after he was murdered. Several traffic fatality survivors described being upset by images of the vehicle wreckage, including Catherine, whose son was among those killed in a mass casualty collision, and who wrote that an image of the crash scene "was a source of PTSD [post-traumatic stress disorder] for me."

While many survivors who pointed to misinformation as a negative outcome did not specify which details were inaccurately reported, some of them mentioned interviews that had been conducted with people who were not close to the deceased.

Some survivors reported being upset that the media did not continue to follow their case after it was initially reported, while others were hurt that the media did not contact them in the days, weeks, and months after they granted highly emotional interviews.

While 65 of the 71 survivors reported at least one negative outcome from their experiences with the media, 52 agreed there was value in survivors sharing their stories publicly. The following section may explain why.

\section{Positive Impacts of the Media}

All but 18 of the 71 respondents reported at least one positive outcome, with 18 positive categories emerging from the surveys. The top six positive outcomes were: the kindness or empathy of reporters (23); the opportunity to share the story of the deceased loved one(s) (18); the feeling of pursuing justice or effecting change (17); the outpouring of community support that followed media coverage (14); the ability to help other survivors (13); and using the media as an avenue for advocacy (12).

Many of these positive outcomes were reported alongside the negatives. For example, Beth, whose husband was murdered in the United States in 2013 and whose case, as of this writing, remains unsolved, wrote that while she was disappointed in the lack of interest in the case as time went by, the media's interest in the immediate aftermath, "Felt good," adding, "I felt like the reporters genuinely cared." Homicide survivor Beverly, who did not like the media attention her family received, pointed out that reporters she encountered were kind and respectful: "I have received flowers and lovely caring letters from different reporters. One man has brought flowers every Christmas for the past three years."

Bridgette wrote that she took comfort in the way the editor of the local paper took her concerns about coverage of her son's homicide seriously, allowing her the opportunity to publish an editorial. And Casna, whose teenage son was killed in Canada in 2008, and who recalled a "complete disrespect of our shock, sorrow, and privacy" in the immediate aftermath of her son's homicide, expressed an appreciation for journalists "who were able to understand that losing [my son] wasn't a story to sell the paper, but tragedy."

Melonie learned of her son's murder in 2018 from Canadian media reports and described the bombardment of messages from reporters as follows: "Like I was thrust into a spotlight I didn't want to be in during the most vulnerable time of my life." Despite these experiences, along with describing insensitive reporting from a local newspaper, Melonie wrote:

Journalists from CTV \& CBC have been understanding, and [they] empowered me to tell my son's story/push for justice. As well, some comments and connections that have come from members of the public in response to seeing a story have been positive and comforting.

An unexpected positive outcome that emerged was the ability to help other survivors. A sentiment shared by several survivors is reflected in the words of homicide survivor Colette, who wrote, "it shows other people that they are not alone."

\section{Advice from Survivors}

Survivors were asked to offer advice in three categories: for other survivors suddenly faced with media coverage; for investigators and/or victim service providers looking to support survivors in engaging or not engaging with the media; for members of the media who are covering traumatic events and who wish to engage with survivors.

From the 71 survey respondents, the question regarding advice for survivors produced 18 categories, four of which were repeated five or more times: only speak when you are ready (11); embrace it (11); appoint a spokesperson (11); and never engage (5). The question regarding advice for investigators and/or victim service providers produced seven categories, three of which were repeated five or more times: offer support (16); be more empathetic, sensitive, or similar (13); and explain rights/process/advice regarding media (12). Advice for the media produced 26 categories, seven of them repeated five or more times: be more empathetic, kind, or 
similar (25); put self in survivors' shoes (13); be respectful (13); be patient (7); only reach out to survivor once (7); check facts (5); and give more coverage to less-reported cases (5).

Among the survivors who implored investigators and/ or victim service providers to provide more support and guidance with the media was Wendy, whose brother's body was found in the United States in 2020, and who wrote: "Give them an advocate immediately. Help them to understand the process and options." Matt, whose loved one was killed in a Canadian traffic fatality in 2017, shared these sentiments, adding, "I felt lost in the days following the death of my family member."

Asked if there was anything she thought could have made her experience with the media easier, less traumatic, or more beneficial for her, homicide survivor Bridgette wrote, in part:

People, in general, often don't realize that just because a bereaved parent may seem okay, this doesn't mean that she/he is. Mostly it's the numbing benefits of shock and denial that are doing the talking. Tomorrow she/he may be deeply and painfully regretful of every word uttered.

\section{Results from Journalists}

\section{Trauma-Informed Training and Guidelines}

Asked to what extent and in what context they recalled receiving training in covering traumatic events, interacting with victims or survivors, trauma-informed interview techniques and/or trauma-sensitive language before becoming a journalist, none of the 22 journalist respondents reported any meaningful training, though five reported having received some.

One of those five responded, "Hardly at all." Another, "Very little." Another wrote: "In (journalism) school, I was taught the basics of gathering information during traumatic events, but nobody ever talked about trauma or how to interact with victims/survivors aside from a general 'try to be kind' guideline."

Asked to what extent and in what context they'd received such training during their journalism careers, again the majority, 15 , reported receiving none. Four reported receiving very little training, while three described more extensive training.

Asked whether their newsroom has guidelines for interacting with victims or survivors of traumatic events, 18 of the 22 respondents said they were not aware of any guidelines.

\section{Comfort in Contacting Survivors}

Asked how soon after a traumatic event such as a homicide or traffic fatality they generally make their first attempt to contact survivors, 13 of the 22 journalists indicated, "As soon as Ihave the information necessary to do so (i.e., name/address/phone number)." Five others responded, "Within first 24 hours."

Despite these numbers, only five of the journalists indicated they were comfortable reaching out to survivors in the immediate aftermath of traumatic events, though none described it as a positive experience. Five respondents wrote that their level of comfort depended on the situation, including Luis, who worked as a crime reporter for more than 20 years:

I went numb after a few years. Then into survival mode, get the job done and move on, where they were stats rather than human. It was a survival tactic for me. Then later it became a 'duty' to tell the story of the dead. It was a multi-phase roller coaster. It was helpful when I worked with another reporter who felt the same way. It was a nightmare when working with a news person without empathy. And there were a few.

Among the nine respondents who expressed discomfort was a reporter with more than 15 years on the job, who wrote: "It is the worst part of the job, and the thing I like least about my profession." A newsroom manager with more than 20 years in the industry wrote: "I used to have no issues as I believed I was helping them. Then twice I was first to let them know and that is a horrible experience." And from a reporter with more than 10 years' experience:

Oh I absolutely hate it. It causes me a lot of stress and guilt, even when the victims/survivors seem like they want to talk. Because I always worry that they'll regret it, or that we're taking energy from them that they could use for self-care.

\section{Personal Impact of Reporting on Trauma}

Fifteen of the 18 journalists who answered the question, "What impact has covering traumatic events had on you?" reported being impacted negatively, including a reporter with more than a decade on the job, who wrote, in part: "I know that I think about death and dying a lot more than most people I know. I know that I cannot smell a campfire without thinking of the smell of decomposing bodies." One respondent with more than 20 years' experience wrote that they suffer from PTSD, while another with more than 15 years on the job wrote: "I have suffered from vicarious trauma and repetitive stress and it became very difficult to continue in my job without addressing that."

The reporter who wrote that reaching out to survivors in the immediate aftermath "causes me a lot of stress and guilt," later added, "The combination of long hours, stress of navigating a breaking news situation, and trying to not cause additional harm while doing your job-it's heavy and takes a lot out of me." When asked about personal impact, another reporter with more than a decade of experience wrote, "Honestly do not want to contemplate this." When asked about methods of self-care, that same reporter responded, "Drink."

\section{Some Notable Voices of Survivors on Negative Encounters with the Media}

As noted above, dozens of categories emerged when discussing negative outcomes. While some survivors were overwhelmed by an abundance of media attention, others suffered from a lack of attention. Understandably, those who experienced an abundance of attention were able to provide more examples of what contributed to the trauma they experienced from the media. This section serves to highlight some of these anecdotes.

The first experience Heather had with the media following the stabbing of her husband was watching him die on live television.

She had been watching the news, as she did every night, when "breaking news" came on screen, and live pictures were broadcast from the spot where her husband, an on-duty Canadian police officer, had been attacked, she recounted in 
an interview. He had not yet been transported to hospital. Attempts to reach her husband's colleagues were unsuccessful, but Heather knew where he had been working and recognized his undercover van. Her mother recognized his shoes during the live broadcast of him being wheeled into hospital, "vital signs absent."

In her survey, the intensely private Heather described reporters phoning her home, knocking on her door, canvassing neighbours, and hiding behind trees in an attempt to photograph her in the days that followed her husband's murder. Asked how the media attention in the immediate aftermath of her husband's homicide made her feel, Heather wrote: "exposed, ambushed, intimidated, privacy invaded, overwhelmed, pressured, attacked." She was one of seven survivors who described the media as having a direct, negative, long-term impact on them personally.

Homicide survivor Cynthia had a similar experience before her missing husband, an American psychologist, was found murdered. Describing her first encounter with the media after her husband went missing, Cynthia wrote:

I vividly remember the print and visual media came to my door with microphones and vans parked out front in a group. They rather "took over" when I went to answer the phone in the library and took photos of the interior of my house and of me over my objections.

Canadian homicide survivor Whitney described a reporter showing up at her door hours after her son's body was found:

When we refused to talk to him, we found him circling our house in our back yard. He had also gone to our neighbours. He somehow found my elderly in-laws and also went to their house and to their neighbours. As we were talking to him on the street to tell him to leave, another car pulled up with two reporters in it. By this time, we were extremely angry and traumatized by the other reporter. These two could see that, and after we informed them that we would not speak to them, they asked simply to take a picture of one of [my son]'s pictures.

Whitney wrote about a third interaction she had with a reporter who called her home late that night: "He introduced himself, and then he said these exact words, because I will never forget them. 'Mrs. [Smith], we are going to do a story on your son. Do you have anything good to say about him?"' Asked how the attention in the immediate aftermath of her son's homicide made her feel, Whitney wrote: "We felt violated and intimidated. We felt pressured and judged. We felt angry and hunted."

In a small American town where an elderly man had been murdered inside his home, his daughter Susan recalled in her survey that members of the media had been on her father's front porch,

ringing the doorbell while we remained terrified inside the house... It took five days for my Dad's killer to be found...Having the media camp out and follow us from my Dad's house, police station and funeral home was terrifying as we never knew who it was, police, killer or media.
Homicide survivor Barb was stranded overseas when a plane flew into the south tower of the World Trade Center, where her husband had been working on September 11. She wrote in her survey that her "family was 'accosted' by all methods," including at their home, on the phone, and through her husband's employer. The attention in the immediate aftermath was "overwhelming for my family," Barb wrote, adding, "It directly affected my daughter's dream of becoming a journalist."

Asked if there were any aspects of the media coverage of his mother's traffic fatality that he found to be particularly traumatic, one survey respondent wrote:

Seeing a reporter in court on the first day of trial, in the row in front of me where I could see she had a news story of my mother's death on her phone. As though she needed to refresh herself on the details surrounding my mother's death. It was gut wrenching and made me furious. I had to move to the accused side of the court to avoid this reporter. It made me want to rage and lash out towards her, and [it] took everything I had to control myself.

The family member of an American homicide victim wrote that the media began calling immediately after she was notified by the coroner of her loved one's death. Asked how this made her feel, she wrote: "Shocked, attacked, hurt but above all rushed because I didn't have time to notify family." She later described the attention as, "Like sitting in the middle of a hurricane," writing that the attention, "turned my broken heart into a million pieces. It caused great anxiety." Asked if there was anything else she wanted people to know about the impact of the media on survivors, she wrote: "The media traumatized me almost as much as the murder."

\section{DISCUSSION}

The dominant theme that emerged from the surveys and interviews with survivors was the lack of support they received in engaging (or choosing not to engage) with members of the media, particularly in the immediate aftermath of their traumatic loss. Further, the lack of training expressed by the vast majority of journalists illustrates the likelihood that, while survivors may encounter kind, empathetic reporters, those same reporters may not have an adequate, trauma-informed understanding of how to interact with survivors without causing further harm. And while some of the journalists acknowledged the harm that their interactions might cause, so too did there appear to be an acknowledgement that a viable alternative was lacking, to the detriment of both survivors and journalists.

Only six of the 71 survivors had only positive sentiments about the media. Of those six, five used the media to publicly advocate against issues that were connected to their case, such as impaired driving or perceived deficiencies in the justice system. Four of the six were not contacted in the immediate aftermath of their traumatic event. Of the two who were, one described being in such a state of shock that he seemed not to be affected by the media's presence, while the other was able to forge positive relationships with the media during the months that her murdered daughter was still missing-a time when she was eager to work with the media to find her. 
In each of these examples, the survivors with only positive experiences had one thing in common: control. When they wanted to engage with the media, the media was there. In the immediate aftermath, when they were likely most vulnerable, most of them were not contacted at all.

One of the final questions in the survey for homicide and traffic fatality survivors was whether there was anything else they would like people to know about the impact of the media on survivors. Many of them answered this question by giving insight into the survivor experience. One such survivor was Felicity, the mother of a 26-year-old Canadian homicide victim:

The feeling of someone literally reaching into your chest and squeezing your heart for months after. The feeling of surrealness and grief is so overwhelming and for those of us that actually witnessed the effects of what a bullet has done to their loved one, our minds feel like they are going to explode. We are not even aware of what is going on around us, it's like you are outside of your body watching yourself. We are going through the motions of the day, but not really aware of what we are doing or saying.

\section{CONCLUSION}

When discussing the experiences of trauma survivors with the media, a triangle emerges. On the three points are the media, victim service providers, and the justice system, such as investigators and prosecutors. In the middle of the triangle is the survivor. Problematically, while each of the three actors is working with or for the survivor, there does not appear to be any standard for them to work together.

While most survivor surveys made no mention of a victim service provider or investigator supporting them with the media, some of those who did pointed out that they were not in touch with a victim service provider until after the onslaught of media requests. Access to survivor support and the timing of such supports are issues that should be explored further.

I would also like to see research on the impact of images that are often used in news media but that survivors find traumatizing: the homicide victim in a body bag, the wreckage from the traffic fatality. Do these images do more harm than good, or the other way around? One substantial study on trigger warnings in the media showed them to be ineffective in helping trauma survivors (Jones et al., 2019), but could harm be mitigated if a practitioner warned the survivor about these images ahead of time, so they could avoid the news coverage all together?
Most survivors in this project reported negative outcomes with the media, yet most agreed there is value in survivors sharing their stories publicly. Are those negative outcomes then the necessary means to the beneficial end? Or is there a way to re-imagine the system so that it is beneficial to all stakeholders-a system that does not cause harm to survivors, or the journalists tasked with telling their stories?

It is my hope that this article will spark conversations both within the fields of criminal justice, news media and survivor support, and between them. Perhaps once these different sectors understand each other, learn from each other, and choose to work together, the negative impacts reported in this article can be mitigated or eliminated.

\section{CONFLICT OF INTEREST DISCLOSURES}

Tamara Cherry is the founder of Pickup Communications, a public relations firm that supports victims and survivors of traumatic events and works with various partners in the criminal justice sector. The work for victims and survivors is done on a pro bono basis or is funded by organizations serving the victims and survivors. No funding was sought or received for this project.

\section{AUTHOR AFFILIATIONS}

*Pickup Communications, Regina, SK, Canada

\section{SUPPLEMENTAL MATERIAL}

Supplemental information linked to the online version of the paper at journalcswb.ca:

\section{Video S1}

\section{REFERENCES}

Bucqueroux, B., \& Seymour, A. (2009). A guide for journalists who report on crime and crime victims. Justice Solutions.

Considerations for victims and survivors in dealing with the media. (2011). Canadian Resource Centre for Victims of Crime. crcvc.ca.

Durham, A. M., Elrod, H. P., \& Kinkade, P. T. (1995). Images of crime and justice: Murder and the "true crime" genre. Journal of Criminal Justice, 143-152.

Jones, P. J., Bellet, B. W., \& McNally, R. J. (2020). Helping or harming? The effect of trigger warnings on individuals with trauma histories. Clinical Psychological Science, 815), 905-917. https://doi.org/10.31219/ osf.io/axnbz

Newton, J., \& Duncan, S. (2012). Journalists and the bereaved: Constructing a positive approach to the teaching of death reporting. Journalism Education, 1(2), 59-67.

Shepard, A. C. (n.d.). The Columbine shooting: Live television coverage. Columbia University. http://www.columbia.edu/itc/journalism/i6075/edit/ readings/columbine.html

Schildkraut, J. (2012). Media and massacre: A comparative analysis of the reporting of the 2007 Virginia Tech shootings. Fast Capitalism, 9(1), 119-132. 